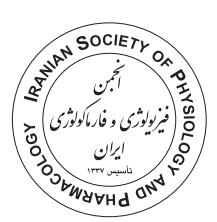

\title{
Antidepressant efficacy of MLC901 in the 6-hydroxydopamine mice model of Parkinson's disease
}

Mohaddeseh Ebrahimi-Ghiri', Sakineh Alijanpour ${ }^{2}$, Fatemeh Khakpai ${ }^{3^{*}}$ (DD), Mohammad-Reza Zarrindast ${ }^{4,5,6}$

1. Department of Biology, Faculty of Sciences, University of Zanjan, Zanjan, Iran

2. Department of Biology, Faculty of Science, Gonbad Kavous University, Gonbad Kavous, Iran

3. Cognitive and Neuroscience Research Center (CNRC), Tehran Medical Sciences, Islamic Azad University, Tehran, Iran

4. Department of Pharmacology School of Medicine, Tehran University of Medical Sciences, Tehran, Iran

5. Iranian National Center for Addiction Studies, Tehran University of Medical Sciences, Tehran, Iran

6. Department of Neuroendocrinology, Endocrinology and Metabolism Clinical Sciences Institute, Tehran University of Medical Sciences, Tehran, Iran

\begin{abstract}
Introduction: Depression is a common mood disorder in patients with Parkinson's disease (PD), which negatively influences the quality of life and enhances caregiver burden. MLC901, a traditional medicine, has been demonstrated to be useful in preclinical and clinical studies. The aim was to study the effect of MLC901 on depression behavior in a mouse model of $\mathrm{PD}$, comprising in the unilateral striatal delivery of the neurotoxin 6-hydroxydopamine (6OHDA).

Methods: Female NMRI mice were divided into the following groups: sham/saline group, 6-OHDA/saline group, sham/MLC901 $(40 \mu \mathrm{g} / \mathrm{kg})$ group and 6-OHDA/MLC901 group. Intraperitoneal treatments of MLC901 were started one week after the stereotaxic surgery that continued for 4 weeks (5 days/week). Locomotion was monitored using an openfield test and depressive-like responses were measured by forced swim test (FST) and tail suspension test (TST).

Results: We found that MLC901 prevented the increased immobility time in the PD mice in both FST and TST, suggesting an antidepressant efficacy for the MLC901. None of the treatments alter locomotion compared to the sham group.

Conclusion: In conclusion, we propose that MLC901 is a potential candidate to be used in studies for the treatment of depression in PD.
\end{abstract}

Keywords:

Parkinson's disease

MLC901

Forced swim test

Tail suspension test

\section{Introduction}

Besides motor dysfunction, depression is one of the most typical non-motor syndromes, occurring in around $35 \%$ of Parkinson's disease (PD) patients (Reijnders et al., 2008). Along with the progression of $\mathrm{PD}$, depression has been correlated with declined functioning, cognitive disruption and increased stress, which considerably contribute to the substandard quality of life for PD patients (Kadastik-Eerme et al., 2015). Neuroimaging evidence has indicated that depression in PD was the result of re-

\footnotetext{
* Corresponding author: Fatemeh Khakpai, khakpai@iautmu.ac.ir

Received 27 November 2020; Revised from 4 February 2021; Accepted 8 February 2021
}

Citation: Ebrahimi-Ghiri M, Alijanpour S, Khakpai F, Zarrindast MR. Antidepressant efficacy of MLC901 in the 6-hydroxydopamine mice model of Parkinson's disease. Physiology and Pharmacology 2021; 25: 328-333. http://dx.doi.org/10.52547/phypha.25.4.4 
gional abnormalities in the basal ganglia, the prefrontal cortex and the limbic system (the ventral striatum, thalamus, amygdala, insula and cingulate cortex) (Etkin et al., 2010; Remy et al., 2005). Hence, the pathophysiology of depressive symptoms in this disease is complex and probably modulates by the neurotransmitter systems of dopaminergic, serotoninergic, noradrenergic and cholinergic (Kamińska et al., 2017). Though L-DOPA remains the most effective treatment for the motor symptoms of PD, its impacts on mood-correlated dysfunctions is constricted and its long-term application worsens depression (Jaunarajs et al., 2012; Nègre-Pagès et al., 2010). Therefore, new treatment strategies are needed to avoid the onset of depression in PD patients.

Interestingly, traditional Chinese medicine MLC901 has played a critical participation in promoting health and disease control for many years ago in Asia. Its possible therapeutic effect is often ascribed to the synergistic characteristic of numerous herbal constituents which provide a combinational therapeutic strategy which ameliorates the efficacy via hitting numerous targets (Heurteaux et al., 2013; Lorivel et al., 2015; Siow, 2008). Recently, this medicine has come out as a hopeful treatment for ameliorating useful recovery of patients afterward ischemic stroke (Siow, 2008). Protective effects of MLC901 on performance of mice in cognitive tasks has been known (Lorivel et al., 2015). Enhanced hippocampal neurogenesis along with promoted proliferation and neuronal differentiation as well as survival of young neurons has been also shown with MLC901. It is supposed that the neurogenesis efficacy of MLC901 is contributed to its pro-cognitive properties (Lorivel et al., 2015). In a recent study, protective effect of MLC901 on memory in Alzheimer's disease patients has been found (Chen et al., 2019). We previously reported that MLC901 abolishes fear memory impairment in the sleep-deprived rats (Nasehi et al., 2019).

Based on the mentioned document, we wanted to examine the effect of MLC901 administration on depressive-like behavior in mouse model of PD produced via the microinjection of 6-OHDA.

\section{Material and methods}

Drugs

The 6-hydroxydopamine hydrochloride (6-OHDA, obtained from Tocris Bioscience) was dissolved in a vehicle solution $(0.9 \%$ sterile saline comprising $0.02 \%$ ascorbic acid). The 6-OHDA dose was chosen based on literature (Alvarez-Fischer et al., 2008). The MLC901 (Moleac, Singapore) combines nine herbal particles with the following composition in each capsule: $0.57 \mathrm{~g}$ Radix astragali, 0.114g Radix Salvia miltiorrhizae, 0.114g Radix Paeoniae rubra, 0.114g Rhizoma chuanxiong, 0.114g Radix Angelicae sinensis, 0.114g Carthamus tinctorius, 0.114g Prunus persica, 0.114g Radix polygalae and $0.114 \mathrm{~g}$ Rhizoma acori tatarinowii. Ketamine hydrochloride and xylazine (Alfasan, Woerden, Holland) used for animals anesthetization. Animals received saline $(10 \mathrm{ml} / \mathrm{kg})$ or MLC901 $(40 \mu \mathrm{g} / \mathrm{kg}$, intraperitoneally) for four weeks (5 days/week). The volume of administration was $10 \mathrm{ml} / \mathrm{kg}$. MLC901 dose was selected based on (Widmann et al., 2018).

\section{Animals}

Female NMRI mice (6-8 weeks old, 28-32g) were kept eight per cage under standard controlled laboratory conditions (12h light/dark cycle, light on at 07:00am, $22 \pm 2^{\circ} \mathrm{C}$, pelleted food and water ad libitum). All experiments performed upon the ethical principles confirmed in the Guide for the National Institutes of Health Guide for the Care and Use of Laboratory Animals (NIH publications No. 85-23) as well as approved by the Animal Care and Research Ethics Committee of Tehran Medical Sciences (Islamic Azad University).

\section{Experimental plan}

The mice were anaesthetized with a mix of xylazine $(10 \mathrm{mg} / \mathrm{kg})$ with ketamine $(100 \mathrm{mg} / \mathrm{kg})$ and positioned in a stereotaxic frame. Mice received bilateral microinjection of 6-OHDA $(4 \mu \mathrm{g} / \mu \mathrm{l}, 0.5 \mu \mathrm{l} / \mathrm{each}$ site) into the dorsal-lateral striatum (coordinates: AnteriorPosterior: +0.9 ; lateral about the sagittal line: Lateral: \pm 1.8 ; vertically from the top of the skull: Ventral: -3.2 ). Sham mice were microinjected with the similar volume of vehicle $(0.9 \%$ sterile saline and $0.02 \%$ ascorbic acid). Afterwards, the animals returned to their cages for recovering (one week). A total of 32 mice were divided into four groups $(n=8)$, including: sham group received saline $(10 \mathrm{mg} / \mathrm{kg}), 6-$ OHDA group received saline $(10 \mathrm{mg} / \mathrm{kg})$, MLC901 in non-PD mice and MLC901 in PD mice. The compounds were tested at doses: saline (10mg/kg), 6-OHDA $(4 \mu \mathrm{g} / \mu \mathrm{l})$ and MLC901 $(40 \mu \mathrm{g} / \mathrm{kg})$. MLC901 administrations were started one week after 
the surgical procedure for four weeks (5 days/week). Then, $24 \mathrm{~h}$ afterward the last drug injection, the mice were submitted to the behavioral tests.

\section{Behavioral testing}

\section{Open-field test}

The open-field apparatus was comprised of white opaque Plexiglas $\left(50 \times 50 \times 30 \mathrm{~cm}^{3}\right)$. The floor was partitioned to four quadrants of equal part. At the time of test, the device was illuminated by a dim light. Number of crossings with all paws from one part to another as an index of locomotor activity was observed for $5 \mathrm{~min}$ (Alijanpour et al., 2019).

\section{Forced swimming test (FST)}

The FST was performed $5 \mathrm{~min}$ after the open-field test. Animals were positioned into a cylindrical container $(10 \mathrm{~cm}$ in diameter, $25 \mathrm{~cm}$ in height, $10 \mathrm{~cm}$ in water depth) filled with water and maintained at $23-25^{\circ} \mathrm{C}$. Immobility time was measured for the period of the last $4 \mathrm{~min}$ of the total 6 min swimming. Immobility means that animals end swimming and make no active movement (Alijanpour et al., 2019).

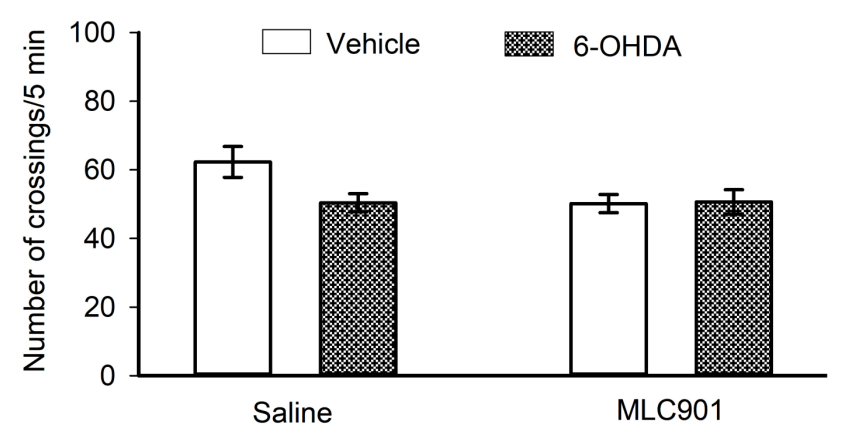

FIGURE 1. Effect of MLC901 on locomotor activity of PD mice in the open-field test. Values are mean $\pm \operatorname{SEM}$ ( $\mathrm{n}=8$ in each group). 6-OHDA: 6-hydroxydopamine

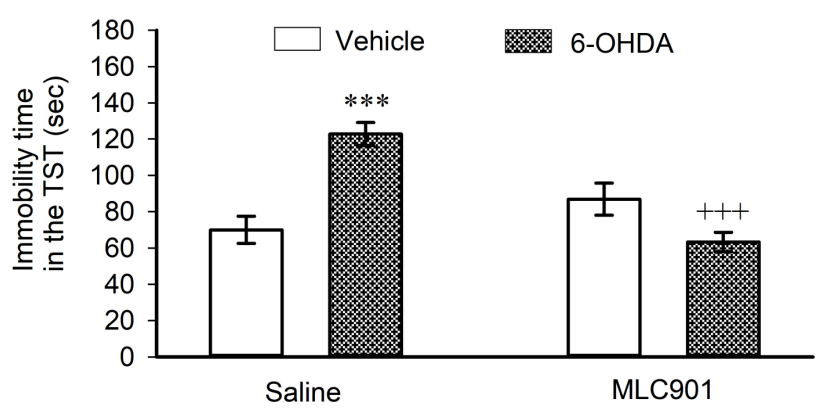

\section{Tail suspension test (TST)}

The TST was done $1 \mathrm{~h}$ after the FST. Animals were suspended from the upper of a lever with their tail fixated on a hook via insertion adhesive tape (about $1 \mathrm{~cm}$ from the tail tip). The immobility time was measured in the course of the last $4 \mathrm{~min}$ of the total $6 \mathrm{~min}$ suspension. Immobility means that animals end struggling and stay motionless (Alijanpour et al., 2019).

\section{Data analysis}

For statistical analysis, one-way ANOVA followed by Tukey Post Hoc analysis was used for numerous comparisons. The $P<0.05$ was considered significant.

\section{Results}

Effect of MLC801 treatment on locomotor activity in PD mice

One-way ANOVA and Post-Hoc analysis exhibited that PD mice tended to decreased locomotor activity $[\mathrm{F}(3,28)=3.01, P=0.125]$ compared to the vehicle/saline group, although it was not significant. MLC901 did not alter locomotion in vehicle-treated mice or PD mice. As a result, PD mice showed a mild motor impairment.

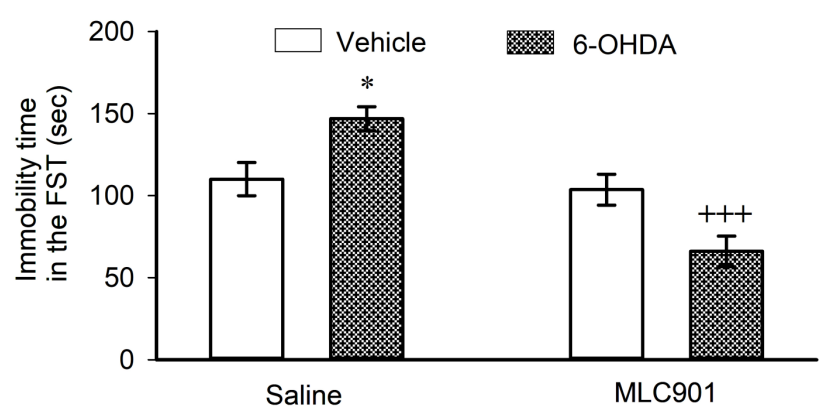

FIGURE 2. Effect of MLC901 on immobility time of PD mice in the FST. Values are mean \pm SEM (n 8 in each group). ${ }^{*} P<0.05$ compared to the vehicle/saline group; ${ }^{++} P<0.001$ compared to the 6-OHDA/saline group. 6-OHDA: 6-hydroxydopamine; FST: forced swimming test.

FIGURE 3. Effect of MLC 901 on immobility time of PD mice in the TST. Values are mean \pm SEM ( $n=8$ in each group). ${ }^{* * *} P<0.001$ compared to the vehicle/saline group; ${ }^{+++} P<0.001$ compared to the 6-OHDA/saline group. 6-OHDA: 6-hydroxydopamine; TST: tail suspension test. 
Effects of MLC901 treatment on immobility time in the FST in PD mice

One-wayANOVA and Post-Hoc analysis demonstrated that PD mice significantly increased immobility time $[\mathrm{F}(3,28)=13.171, P<0.001]$ in the FST compared with vehicle/saline group, but PD mice treated with MLC901 decreased this parameter compared to the $\mathrm{PD} /$ saline group. As a result, PD mice showed a depressive-like property but MLC901 could prevent this effect in the PD mice.

\section{Effects of MLC901 treatment on immobility time in the TST in PD mice}

One-way ANOVA and Post-Hoc analysis displayed that PD mice enhanced immobility time $[\mathrm{F}(3,28)=$ 13.884, $P<0.001]$ in the TST compared with vehicle/ saline group, while PD mice treated with MLC901 decreased this parameter compared to the $\mathrm{PD} /$ saline group. As a result, PD mice showed a depressive-like property but MLC901 could prevent this effect in the PD mice.

\section{Discussion}

We found that MLC901, a traditional Chinese medicine, prevents depressive behavior and locomotor activity dysfunction in Parkinson's mice of 6-OHDA model. We created the PD model presented by Bonito-Oliva and coworkers (2014). This study showed that the PD model induced by bilateral infusion of 6-OHDA in the dorsal striatum produces a partial reduction $(70 \%)$ in the dopamine and noradrenaline release (Bonito-Oliva et al., 2014). In line with this study, we observed that PD mice tended to decrease of locomotion in the open-field test, although it was not significant. Moreover, PD mice exerted the depressive-like response in the FST and TST (two standard behavioral paradigms indicative of depression). The 6-OHDA selectively abolishes the dopaminergic nigrostriatal circuit through producing oxidative stress which can cause the production of inflammation and finally cell death (Kaariainen et al., 2008; Lev et al., 2013). In addition, the neurotoxin 6-OHDA rapidly exerts non-enzymatic oxidation which produces superoxide and hydrogen peroxide as well as hydroxyl radicals (Soto-Otero et al., 2000). It seems that 6-OHDA, as a last effector of dopamine neural death, elicits a caspase 3-dependent apoptotic signaling (Hanrott et al., 2005; Tanaka et al., 2006); however, this circuit is not partic- ular for 6-OHDA (Hartmann and Hirsch, 2001). Alvarez-Fischer et al. (2008) indicated that the toxicity of 6-OHDA is partially mediated through $\alpha$-synuclein because $\alpha$-synuclein knockout animals are more resistant to 6-OHDA and mechanism of $\alpha$-synuclein toxicity is very probable mediated through reactive oxygen species production. In an animal model of PD, the production of free radicals may cause a enhance in pro-inflammatory cytokines in company with reduced anti-inflammatory particles in the striatum (Barbiero et al., 2014; Pisanu et al., 2014). There is a report that depression associated with PD is related to an alteration in the neuroinflammation-caused serotonergic system (Santiago et al., 2016).

We observed that treatment with MLC901 for four weeks could prevent depressive-like profile induced in PD mice. Recently, it has been reported that MLC901 prevents inflammatory mechanisms afterward focal cerebral ischemia (Widmann et al., 2018). Several preclinical researches have demonstrated a main beneficial influence of MLC901 on stimulation of ATP-sensitive $\mathrm{K}^{+}$channels (Maati et al., 2012), a mechanism revealed to be neuroprotective (Zhang et al., 2016) as well as on the repair mechanism such as neurogenesis or expression of the cortical brain derived neurotrophic factor (Heurteaux et al., 2010). This compound also stimulates serine/threonine kinase Akt (protein kinase B) signaling in model of global ischemia (Franke et al., 1997) and decreases level of the Bax protein as well as induces a reduction of apoptotic mechanisms (Quintard et al., 2011).

\section{Conclusion}

The multifaceted positive effect of MLC901 in neuroprotective and neurorepair processes suggests that this compound can be useful for the treatment of depression in PD.

\section{Acknowledgment}

We are thankful to all contributors for their participation.

\section{Conflict of interest}

There is no conflict of interest in this manuscript.

\section{References}

Alijanpour S, Khakpai F, Ebrahimi-Ghiri M, Zarrindast MR. Co-administration of the low dose of orexin and nitrergic antagonists induces an antidepressant-like effect in 
mice. Biomed Pharmacother 2019; 109: 589-94. https://doi. org/10.1016/j.biopha.2018.10.033

Alvarez-Fischer D, Henze C, Strenzke C, Westrich J, Ferger B, Höglinger GU, et al. Characterization of the striatal 6-OHDA model of Parkinson's disease in wild type and $\alpha$-synuclein-deleted mice. Exp Neurol 2008; 210: 182-93. https:// doi.org/10.1016/j.expneurol.2007.10.012

Barbiero JK, Santiago RM, Persike DS, da Silva Fernandes MJ, Tonin FS, da Cunha C, et al. Neuroprotective effects of peroxisome proliferator-activated receptor alpha and gamma agonists in model of parkinsonism induced by intranigral 1-methyl-4-phenyl-1, 2, 3, 6-tetrahyropyridine. Behav Brain Res 2014; 274: 390-9. https://doi.org/10.1016/j. bbr.2014.08.014

Bonito-Oliva A, Masini D, Fisone G. A mouse model of non-motor symptoms in Parkinson's disease: focus on pharmacological interventions targeting affective dysfunctions. Front Behav Neurosci 2014; 8: 290. https://doi.org/10.3389/ fnbeh.2014.00290

Chen CLH, Sharma PR, Tan BY, Low C, Venketasubramanian N. The Alzheimer's disease THErapy with NEuroaid (ATHENE) study protocol: assessing the safety and efficacy of Neuroaid II (MLC901) in patients with mild-to-moderate Alzheimer's disease stable on cholinesterase inhibitors or memantine-A randomized, double-blind, placebo-controlled trial. Alzheimers Dement 2019; 5: 38-45. https://doi. org/10.1016/j.trci.2018.12.001

Jaunarajs KE, George JA, Bishop C. L-DOPA-induced dysregulation of extrastriatal dopamine and serotonin and affective symptoms in a bilateral rat model of Parkinson's disease. Neuroscience 2012; 218: 243-56. https://doi.org/10.1016/j. neuroscience.2012.05.052

EtkinA, EgnerT, Kalisch R. Emotional processing in anterior cingulate and medial prefrontal cortex. Trends Cogn Sci 2010; 15: 85-93.https://doi.org/10.1016/j.tics.2010.11.004

Franke TF, Kaplan DR, Cantley LC. PI3K: downstream AKTion blocks apoptosis. Cell 1997; 88: 435-7. https://doi. org/10.1016/S0092-8674(00)81883-8

Hanrott K, Gudmunsen L, O’Neill MJ, Wonnacott S. 6-hydroxydopamine-induced apoptosis is mediated via extracellular auto-oxidation and caspase 3-dependent activation of protein kinase Cdelta. J Biol Chem 2005; 281: 5373-82. https:// doi.org/10.1074/jbc.M511560200

Hartmann A, Hirsch EC. Parkinson's disease: the apoptosis hypothesis revisited. Adv Neurol 2001, 86: 143-53.

Heurteaux C, Gandin C, Borsotto M, Widmann C, Brau F, Lhuillier $\mathrm{M}$, et al. Neuroprotective and neuroproliferative ac- tivities of NeuroAid(MLC601, MLC901), a Chinese medicine, in vitro and in vivo. Neuropharmacology 2010; 58: 987-1001. https://doi.org/10.1016/j.neuropharm.2010.01.001

Heurteaux C, Widmann C, ou Maati HM, Quintard H, Gandin C, Borsotto M, et al. NeuroAiD: properties for neuroprotection and neurorepair. Cerebrovasc Dis 2013; 35: 1-7. https://doi.org/10.1159/000346228

Kaariainen TM, Piltonen M, Ossola B, Kekki H, Lehtonen $\breve{S}$, Nenonen T, et al. Lack of robust protective effect of quercetin in two types of 6-hydroxydopamine-induced parkinsonian models in rats and dopaminergic cell cultures. Brain Res 2008; 1203: 149-59. https://doi.org/10.1016/j.brainres.2008.01.089

Kadastik-Eerme L, Rosenthal M, Paju T, Muldmaa M, Taba P. Health-related quality of life in Parkinson's disease: a cross-sectional study focusing on non-motor symptoms. Health Qual Life Outcomes 2015; 13: 1-8. https://doi. org/10.1186/s12955-015-0281-x

Kamińska K, Lenda T, Konieczny J, Czarnecka A, Lorenc-Koci E. Depressive-like neurochemical and behavioral markers of Parkinson's disease after 6-OHDA administered unilaterally to the rat medial forebrain bundle. Pharmacol Rep 2017; 69: 985-94. https://doi.org/10.1016/j. pharep.2017.05.016

Lev N, Barhum Y, Ben-Zur T, Melamed E, Steiner I, Offen D. Knocking out DJ-1 attenuates astrocytes neuroprotection against 6-hydroxydopamine toxicity. J Mol Neurosci 2013; 50 : 542-50. https://doi.org/10.1007/s12031-013-9984-9

Lorivel T, Gandin C, Veyssière J, Lazdunski M, Heurteaux C. Positive effects of the traditional $\mathrm{C}$ hinese medicine MLC 901 in cognitive tasks. J Neurosci Res 2015; 93: 1648-63. https://doi.org/10.1002/jnr.23591

Maati HM, Borsotto M, Chatelain F, Widmann C, Lazdunski M, Heurteaux C. Activation of ATP-sensitive potassium channels as an element of the neuroprotective effects of the Traditional Chinese Medicine MLC901 against oxygen glucose deprivation. Neuropharmacology 2012; 63: 692-700. https://doi.org/10.1016/j.neuropharm.2012.05.035

Nasehi M, Mohammadi A, Ebrahimi-Ghiri M, Hashemi M, Zarrindast MR. MLC901 during sleep deprivation rescues fear memory disruption in rats. Naunyn Schmiedebergs Arch Pharmacol 2019; 392: 813-21. https://doi.org/10.1007/ s00210-018-01612-Z

Nègre-Pagès L, Grandjean H, Lapeyre-Mestre M, Montastruc JL, Fourrier A, Lépine JP, et al. Anxious and depressive symptoms in Parkinson's disease: the French cross-sectionnal DoPaMiP study. Mov Disord 2010; 25: 157-66. https://doi. 
org/10.1002/mds. 22760

Pisanu A, Lecca D, Mulas G, Wardas J, Simbula G, Spiga $\mathrm{S}$, et al. Dynamic changes in pro- and anti-inflammatory cytokines in microglia after PPAR-gamma agonist neuroprotective treatment in the MPTPp mouse model of progressive Parkinson's disease. Neurobiol Dis 2014; 71: 280-91. https:// doi.org/10.1016/j.nbd.2014.08.011

Quintard H, Borsotto M, Veyssiere J, Gandin C, Labbal F, Widmann C, et al. MLC901, a traditional Chinese medicine protects the brain against global ischemia. Neuropharmacology 2011; 61: 622-31. https://doi.org/10.1016/j.neuropharm.2011.05.003

Reijnders JS, Ehrt U, Weber WE, Aarsland D, Leentjens AF. A systematic review of prevalence studies of depression in Parkinson's disease. Mov Disord 2008; 23: 183-9. https:// doi.org/10.1002/mds.21803

Remy P, Doder M, Lees A, Turjanski N, Brooks D. Depression in Parkinson's disease: loss of dopamine and noradrenaline innervation in the limbic system. Brain 2005; 128: 131422. https://doi.org/10.1093/brain/awh445

Santiago RM, Vital MA, Sato MD, Adam GP. Depression in Parkinson's disease is associated with a serotoninergic system change secondary to neuroinflammation. Int J Neu- rol Neurother 2016; 3: 061. https://doi.org/10.23937/2378$3001 / 3 / 6 / 1061$

Siow CH. Neuroaid in stroke recovery. Eur Neurol 2008; 60: 264-6. https://doi.org/10.1159/000155220

Soto-Otero R, Méndez-Álvarez E, Hermida-Ameijeiras Á, Muñoz-Patiño AM, Labandeira-Garcia JL. Autoxidation and neurotoxicity of 6-hydroxydopamine in the presence of some antioxidants: potential implication in relation to the pathogenesis of Parkinson's disease. J Neurochem 2000; 74: 1605-12. https://doi.org/10.1046/j.1471-4159.2000.0741605.x

Tanaka KI, Ogawa N, Asanuma M. Molecular basis of 6-hydroxydopamine-induced caspase activations due to increases in oxidative stress in the mouse striatum. Neurosci Lett 2006; 410: 85-9. https://doi.org/10.1016/j.neulet.2006.08.021

Widmann C, Gandin C, Petit-Paitel A, Lazdunski M, Heurteaux C. The Traditional Chinese Medicine MLC901 inhibits inflammation processes after focal cerebral ischemia. Sci Rep 2018; 8: 1-15. https://doi.org/10.1038/s41598-01836138-0

Zhang Y, Pan S, Zheng X, Wan Q. Cytomembrane ATP-sensitive $\mathrm{K}+$ channels in neurovascular unit targets of ischemic stroke in the recovery period. Exp Ther Med 2016; 12: 1055 59. https://doi.org/10.3892/etm.2016.3373 